\title{
Número Especial
}

\section{Políticas de Inclusión y Extensión de la Obligatoriedad Escolar}

\section{archivos analíticos de políticas educativas}

Revista académica evaluada por pares, independiente, de acceso abierto y multilingüe

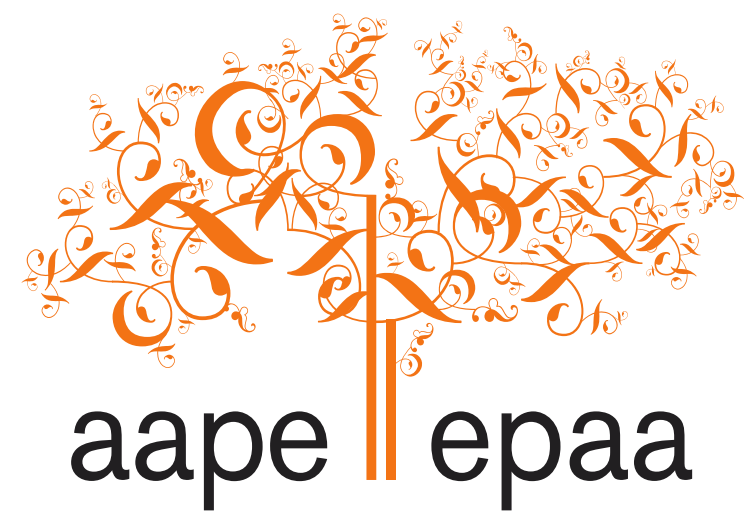

Universidad de San Andrés y Arizona State University

ISSN 1068-2341

\section{Inclusión Educativa y Derecho a la Educación. La Disputa de los Sentidos}

\author{
Ingrid Sverdlick \\ Universidad Nacional Arturo Jauretche \\ Argentina
}

Citación: Sverdlick. I. (2019). Inclusión educativa y derecho a la educación: La disputa de los sentidos. Archivos Analiticos de Políticas Educativas, 27(26). http://dx.doi.org/10.14507/epaa.27.3197 Este artículo forma parte del número especial, Políticas de Inclusión y Extensión de la Obligatoriedad Escolar, editado por Nora Gluz, Dalila Andrade Oliveira, y Cibele Rodrigues.

Resumen: Este artículo analiza, desde una perspectiva histórica, la disputa política sobre los sentidos que el derecho a la educación y la inclusión educativa han tenido en los diferentes modelos o propuestas educativas a lo largo del tiempo y su particular configuración en la actualidad. Es un análisis que incorpora una mirada sobre las luchas de poder que se dan en el campo discursivo, entendiendo que los sentidos que pueden tener las palabras y los conceptos asociados a ellas, ocupan campos que no son solamente campos teóricos o del discurso, sino que también son campos de práctica política. Por otra parte, esta reflexión política se complementa con un análisis crítico sobre las prácticas escolares relativas a la inclusión educativa, a partir de considerar los resultados de una investigación que indagó sobre las formas de apropiación de la política pública en escuelas secundarias con proyectos de inclusión educativa de la Provincia de Buenos Aires, Argentina entre 2013 y 2015. Particularmente nos interesamos por los sentidos y tensiones que asume la inclusión 
educativa en los discursos y prácticas de directivos y docentes, tanto como por los aspectos de la vida cotidiana escolar que limitan y ponen en tensión dichas conceptualizaciones, discursos y prácticas.

Palabras clave: Derecho a la educación; inclusión educativa; sentidos y prácticas de la inclusión

\section{Educational inclusion and the right to education: The senses in dispute}

Abstract: This article discusses, from a historical perspective, the political dispute over the senses that the right to education and inclusive education have been in different models or educational proposals over time and its particular configuration in the today. It is an analysis that incorporates a look over power struggles that they occur in the field of discourse, understanding the senses that can have the words and the concepts associated with them, to occupy fields that are not only theoretical or speech fields, but they are also fields of political practice. On the other hand, this political reflection is complemented with a critical analysis of school educational inclusion practices, from seeing the results of a research that asked about the forms of appropriation of public policy in secondary schools with projects of educational inclusion of the province of Buenos Aires, Argentina between 2013 and 2015. We are particularly interested in the senses and tensions that assumes the educational inclusion in the discourses and practices of principals and teachers, as much as by the aspects of school life that limit and put in tension these conceptualizations, discourses and practices. Key words: right to education; educational inclusión; senses and practices about inclusion

\section{Inclusão educacional e direito à educação: A disputa dos sentidos}

Resumo: Este artigo discute, de uma perspectiva histórica, a disputa política sobre os sentidos que o direito à educação e educação inclusiva foram em diferentes modelos ou propostas educacionais ao longo do tempo e a sua configuração particular na hoje. É uma análise que incorpora um olhar sobre as lutas de poder que ocorrem no campo do discurso, compreendendo os sentidos que podem ter as palavras e os conceitos associados a eles, para ocupar os campos que não são apenas teóricos ou campos de discurso, mas eles também são campos de prática política. Por outro lado, está reflexão política é complementada com uma análise crítica das práticas de inclusão educacional de escola, de ver os resultados de uma pesquisa que perguntou sobre as formas de apropriação das políticas públicas nas escolas secundárias com projetos de inclusão educacional da província de Buenos Aires, Argentina entre 2013 e 2015. Estamos particularmente interessados nos sentidos e as tensões que pressupõe a inclusão educacional nos discursos e práticas de diretores e professores, tanto quanto pelos aspectos da vida escolar que limitam e colocar em tensão essas conceituações, discursos e práticas.

Palavras-chave: direito à educação; inclusão educacional; sentidos e práticas de inclusão 


\section{Inclusión Educativa y Derecho a la Educación. La Disputa de los Sentidos ${ }^{1}$}

\section{Introducción}

¿Cómo se han ido construyendo los diferentes sentidos sobre el derecho a la educación y sobre la inclusión educativa? ¿Cómo juegan esos sentidos en las prácticas concretas en las escuelas secundarias con proyectos de inclusión educativa en la Provincia de Buenos Aires, Argentina? Estos interrogantes fueron emergiendo en el transcurso del desarrollo de una investigación realizada entre 2013 y 2015 sobre las prácticas de gestión y conducción en escuelas secundarias con proyectos de inclusión ${ }^{2}$ y se fueron articulando con la propuesta original de conocer las lógicas de funcionamiento de la organización y del gobierno institucional a la hora de implementar y desarrollar políticas inclusivas. En concreto, en nuestro estudio nos interesamos por analizar cómo se deciden, implementan y realizan las políticas de inclusión en las instituciones, así como también cuáles son las formas de apropiación de las políticas públicas y de generación y gestión de estrategias particulares de inclusión. Pudimos observar, entre otras cuestiones, cómo en las escuelas secundarias se entrecruzan discursos y prácticas, prescripciones normativas y dinámicas institucionales, dando realidad a "la inclusión educativa" desde sus tensiones, contradicciones y realizaciones.

En este artículo se busca compartir las reflexiones que se pudieron sistematizar a partir de las conclusiones del estudio, tanto en términos de debates políticos, como en relación con las prácticas escolares y la mirada de los actores sobre el derecho a la educación y la inclusión educativa. Pensamos que se trata de un tema vigente que involucra cuestiones de orden político e ideológico sobre el sentido de la educación y que requiere sostenerse desde una lucha que impida la vulneración de los derechos adquiridos.

En el momento actual de retroceso en materia de derechos en gran parte de América Latina, con una revitalización enfurecida de las políticas neoliberales, es cada vez más importante generar espacios de resistencia y de lucha política para continuar insistentemente con una lucha que no es sólo por la inclusión sino por la realización efectiva del derecho a la educación.

\section{Los Sentidos Educativos en Disputa}

Los debates educativos inevitablemente circulan y acontecen en diferentes planos del campo educativo y tienen un grado de incidencia muy diverso en las cuestiones que se plantean en las prácticas institucionales y de enseñanza en las escuelas. De hecho, una de las razones por las cuales

\footnotetext{
${ }^{1}$ Este artículo contiene reflexiones y producciones realizadas en forma conjunta con el equipo de investigación que dirigí entre 2012 y 2014 y que dieron lugar a la publicación del libro Sverdlick, Austral, Bloch y Sanchez (2017). Va mi agradecimiento a Rosario Austral, Melina Bloch y Mariana Sánchez. ${ }^{2}$ La investigación referenciada se trató de un estudio de casos con la incorporación de estrategias metodológicas participativas. En una primera etapa, se convocó a la totalidad de los directivos de escuelas secundarias con proyectos de inclusión educativa de la Región V de la Provincia de Buenos Aires (zona de influencia de la Universidad) para la realización de un taller participativo. Uno de los resultados de dicho taller, fue la selección de ocho casos: directoras y directores con quienes realizamos otro taller de cuatro encuentros. En una segunda etapa se seleccionaron cuatro escuelas para profundizar el trabajo. Decidimos concentrarnos en cuatro escuelas de la región, que tuvieran proyectos de inclusión y con características diferentes: una escuela urbana marginal, una escuela rural, una escuela urbana céntrica y una escuela de una barriada popular. Cabe destacar que nuestro posicionamiento epistemológico y consecuentemente la estrategia metodológica empleada se corresponde con los enfoques cualitativo, participativo y crítico. No buscamos verificar hipótesis sino que nuestros supuestos son orientadores del proceso de investigación. En el mismo sentido, nuestros casos tienen la potencia de mostrar en profundidad situaciones, sentidos y relaciones contextualizadas que pueden aportar conocimiento tanto para quienes son los protagonistas de dichas realidades, como para el campo académico que estudia problemáticas análogas o conexas.
} 
existe una percepción generalizada de distanciamiento entre las problemáticas que emergen a nivel de las instituciones escolares y las cuestiones o lineamientos que se discuten y proponen en los ámbitos políticos y académicos, está en relación a que los temas sobre los cuales se discute en educación, al igual que en otros ámbitos de la política pública, van cambiando su énfasis con el tiempo en función de las pujas y tensiones que se generan entre los diversos sectores, intereses e ideologías por la instalación de ciertos asuntos y perspectivas en la agenda política sin considerar necesariamente el diálogo con las escuelas. Con otras palabras, y aunque parezca una obviedad, no está de más explicitar que la educación es un campo político de disputa y como tal, los conceptos, que en apariencia generan consenso, como por ejemplo, la afirmación del derecho a la educación y la inclusión educativa, cobran sentidos diferenciales en función de las prácticas y de los posicionamientos políticos que los enuncian.

Podemos recordar por ejemplo, cómo durante los años de aplicación de las reformas neoliberales (década del 80-90) los principios rectores de las propuestas reformistas: eficiencia, eficacia y racionalidad desde una lógica economicista, se enmarcaban en las mismas ideas que promovían una reforma política del Estado ${ }^{3}$. Los ejes discursivos que definieron y atravesaron la agenda en aquel contexto estuvieron regidos por imperativos económicos que supuestamente mostraban una realidad técnicamente incuestionable y se presentaban como neutrales, verdaderos y “a-políticos”. En el ámbito de la educación, la descentralización, la evaluación, la calidad, el gerenciamiento, las escuelas eficaces, la educación como un servicio, entre otros, tuvieron un lugar preferencial en un discurso centrado en lograr la equidad. Esta idea finalista sustituyó a la idea de equidad como estrategia para lograr una igualdad sustantiva y realizar el derecho a la educación ${ }^{4}$. Este recordatorio, hoy es, además de un ejemplo de conceptos que se instalan en el marco de ciertas políticas, sobre todo una alerta por lo que está regresando a la región latinoamericana de la mano de los gobiernos neoliberales que de una forma más salvaje que antaño, están aplicando las mismas políticas.

Antes de este retorno del neoliberalismo, las críticas a las reformas neoliberales de finales de los 90 y principios del 2000 se expandieron y profundizaron impulsados por el protagonismo que cobraron las luchas de los movimientos sociales y sindicales. Ese impulso, sumado a la asunción y permanencia de nuevos gobiernos progresistas en América Latina, recolocó a la política en un lugar preponderante por sobre la economía. Esto es, se puso en evidencia que, tanto las decisiones económicas como las negociaciones que orientan el rumbo de los países y el accionar de los gobiernos son de índole política y refieren a la definición de un modelo de país y de desarrollo. En ese contexto, el derecho a la educación (re)ingresó como temática en las agendas públicas nacionales e internacionales conjuntamente con la cuestión de la exclusión, la inclusión y la justicia social educativa. En efecto, al iniciar el siglo XXI, la inclusión como discurso y las políticas inclusivas en el

${ }^{3}$ Los procesos de reforma estatal, iniciados en la década de los '90, implicaron un cambio en el rol asignado al estado y, muy especialmente, una profunda transformación de su articulación con la sociedad (Oszlak, 1997). Las principales direcciones de esta reforma (privatización, desregulación, descentralización, reducción de aparato y del personal estatal, etc.) frecuentemente construyeron su "necesariedad" en una valoración positiva, absoluta, de los criterios que orientaban la actividad empresarial, por confrontación con aquellos que se presentaban como propios de la actividad estatal. En este sentido, la iniciativa privada, sus prioridades, sus pautas, o sus estilos de gestión, se convirtieron en sinónimo de modernización (Alonso \& Bra Sverdlick, 2003).

${ }^{4}$ Flavia Terigi (2010) realiza una crítica a la idea finalista de equidad y en su análisis señala que, partiendo de un reconocimiento de la desigualdad que se debe compensar, la política de la equidad conduce al planteo de una educación básica, de unas competencias básicas, de unos estándares comunes a todos. Sin embargo esta idea no es suficiente para el reconocimiento de la alteridad; lo cual es indispensable para lograr una educación realmente democrática e igualitaria. 
campo social tuvieron un rol protagónico en los países latinoamericanos con gobiernos progresistas o "posneoliberales", (así llamados por Emir Sader"). Se trató de una construcción conceptual y política, producto de un proceso que supuso poner en debate la idea misma de inclusión, cuestionando a la educación como instrumento del proyecto de dominación que imponía las formas de participación, los diseños institucionales y buscaba crear un tipo de sujeto acorde a la sociedad imaginada. Esto es, se buscó apartarse del sentido reproductor que implicaba la mera inserción o reinserción de los individuos en un sistema expulsivo. La actuación de los movimientos sociales y sus luchas por el derecho a la educación tuvo mucho que ver en este cambio de sentido ${ }^{6}$. En Argentina, durante la crisis de 2001, los movimientos sociales discutieron fuertemente las estrategias educativas de un sistema que había sido expulsivo y que volvería a serlo por su propia estructura y funcionalidad. Para ellos, la lucha por los derechos humanos y sociales, particularmente, la lucha por el derecho a la educación era también y fundamentalmente una lucha por la reforma democrática del Estado y por una redefinición del sentido de lo público en las sociedades latinoamericanas contemporáneas. La educación se presentaba como un derecho vinculado a otros derechos e imposible de escindir. Desde ese posicionamiento, se generaron propuestas educativas alternativas como los "bachilleratos populares" que pusieron sobre el tapete nuevos problemas. Se trató de iniciativas de educación inclusiva y participativa, presentadas como un proyecto de resistencia a la política excluyente de orientación neoliberal y con otra mirada sobre cómo se resuelven los problemas derivados de los obstáculos que presenta el sistema educativo formal. Abarcó lo que se consideraba un espacio "periférico", fundamentalmente por la presencia de una población fuera de la edad escolar tradicional y de jóvenes que habían repetido o desertado en más de una oportunidad. El fundamento de su condición de "alternativa" se basó en la construcción de subjetividades críticas capaces de participar, opinar, discutir y forjar nuevos destinos, evitando reproducir los clásicos mecanismos expulsivos del nivel de jóvenes y adultos (Sverdlick, 2008, 2009, Elisalde, 2013). Los bachilleratos populares ofrecieron y ofrecen todavía en la actualidad una nueva oportunidad educativa para jóvenes y adultos en el marco de instituciones que desburocratizan la toma de decisiones y generan un vínculo de diálogo entre docentes y estudiantes promoviendo otros modos de enseñar y de aprender. Sin duda que se trata de espacios que habilitan la recuperación de identidades, una mayor conciencia sobre los derechos humanos y sociales, la revalorización de las personas y la reconstrucción de la autoestima perdida por haber retomado trayectorias educativas truncas.

Ahora bien, el debate sustantivo sobre el derecho a la educación y la alternatividad de una propuesta decolonizadora y contrahegemónica colocó otra voz en la escena, pero no logró atravesar las tendencias diluyentes de los organismos internacionales para genera consensos sobre "banderas" que pueden sostenerse de igual manera por cualquier postura (hasta antitética), como lo es la del derecho a la educación. Así, los debates muchas veces se perdieron en argumentaciones jurídicas y/o técnicas, y desde hace tiempo que el derecho a la educación es una afirmación que difícilmente se cuestione o se discuta. Incluso sería políticamente incorrecto oponerse a la educación como un

\footnotetext{
${ }^{5}$ Para el autor, los gobiernos que define como "posneoliberales", se caracterizan por dar prioridad a las políticas sociales en lugar del ajuste fiscal; por la primacía de la integración regional y los intercambios SurSur, frente a la firma de Tratados de Libre Comercio (TLC) con Estados Unidos y por ser gobiernos que impulsan el "rescate" del estado. Apuestan por estados fuertes con un rol activo en lo político, lo económico y para la garantía de los derechos sociales, contra la centralidad del mercado. Existen otras denominaciones y debates referidos a como nombrar a los gobiernos que asumieron en América Latina a partir de 1999 (Chavez) y que supusieron un intento por contraponerse a las políticas neoliberales hegemónicas en la región.

${ }^{6}$ Ejemplos de movimientos sociales y las luchas por el derecho a la educación en América Latina pueden encontrarse en Sverdlick y Gentili (2008).
} 
derecho, máxime cuando la doctrina de los derechos humanos goza del reconocimiento de las Naciones Unidas y ha cristalizado en una vasta normativa internacional a lo largo del último siglo ${ }^{7}$. Esta normativa declara y estipula los compromisos de los Estados en torno del respeto, la protección y la garantía de los Derechos Humanos. Si bien aún existen países que tienen esta materia pendiente en sus legislaciones; tanto a nivel internacional, cuanto a nivel nacional en la mayoría de los países de América Latina, entre los que se cuenta la Argentina, se reconoce que la legislación orientada a garantizar el derecho a la educación es bastante prolífica. A pesar de esto y aunque la escolarización se haya universalizado y extendido ampliamente a partir de la segunda mitad del siglo $\mathrm{XX}$, los estudios e informes de los organismos regionales dan cuenta de una desigualdad persistente y de grandes dificultades para lograr universalizar el acceso, conseguir la permanencia, particularmente en la escuela secundaria y además que se produzcan experiencias de aprendizaje significativas y valiosas para todos. De aquí que, si se piensa que los derechos asumen la igualdad fundamental de las personas y en tanto tales, son universales; es decir, abarcativos a la totalidad, se cumplen o se vulneran, sin que puedan cumplirse parcialmente, estamos en presencia de una realidad que se presenta disociada entre el cumplimiento formal y el efectivo. Formalmente el derecho está garantizado por la legislación; en la práctica es efectivo su incumplimiento.

La afirmación que en 2008 sintetizaba las orientaciones de la agenda política regional y que hacía referencia al derecho a la educación se enunció como: "Educación de calidad para tod@s". Con este enunciado general y polisémico se buscó contener los debates históricos referidos a la desigualdad educativa, incorporando la idea de educación inclusiva. De acuerdo con un documento síntesis de UNESCO que analizó los informes nacionales presentados a la Conferencia Internacional de Educación de $2008^{8}$, en la mayoría de los países de la región, la educación era considerado como un derecho humano fundamental y el reto principal de la política educativa era asegurar una educación de calidad para todos. Según el informe, tanto la calidad como la equidad estaban en el centro de la atención de las políticas educativas nacionales y aunque existía un reconocimiento que la educación no estaba logrando compensar otras diferencias sociales sino que contribuía a reproducirlas ${ }^{9}$, la visión comprehensiva de la inclusión parecía todavía incipiente. En 2015, se encomendó a la UNESCO a dirigir y coordinar la agenda Educación 2030, que se plasmó en el

\footnotetext{
${ }^{7}$ Los principales instrumentos del derecho internacional en materia de derechos humanos se plasman en: La Declaración Universal de Derechos Humanos (1948), la Convención contra la Discriminación en la Educación (1960), la Convención Internacional sobre la Eliminación de todas las formas de discriminación Racial (1965), el Pacto Internacional de Derechos Civiles y Políticos (1966), el Pacto Internacional de Derechos Económicos, Sociales y Culturales (1966), la Convención sobre la Eliminación de todas las formas de Discriminación contra la Mujer (1979), la Convención sobre los Derechos del Niño (1989). En el ámbito regional, se agregan: la Convención Americana sobre Derechos Humanos (Pacto de San José, 1969) y su Protocolo adicional en materia de Derechos Económicos, Sociales y Culturales (Protocolo de San Salvador). Además se pueden mencionar las conferencias multilaterales como "La Conferencia Mundial de Educación de Jomtien, Tailandia (1990), la Declaración de Hamburgo sobre el Aprendizaje de las Personas Adultas (1997) y el Foro Mundial de Educación de Dakar, Senegal (2000), en los cuales se propuso la línea de acción Educación para Todos. La relevancia que ha cobrado este derecho se vislumbra a través del establecimiento de una Relatoría Especial de la Comisión de Derechos Humanos sobre el Derecho a la Educación, bajo la órbita del Alto Comisionado de las Naciones Unidas para los Derechos Humanos.

${ }^{8}$ El documento se titula "La educación inclusiva en América Latina y el Caribe: Un análisis exploratorio de los Informes Nacionales presentados a la Conferencia Internacional de Educación de 2008”. Fue preparado por Massimo Amadio, especialista principal del programa. UNESCO - OEI.

${ }^{9}$ Esta idea de un déficit educativo como una cuestión estructural que se reproduce está expresada en el documento "Situación educativa de América Latina y el Caribe: Garantizando la educación de calidad para todos", publicado por UNESCO - OREALC, Santiago de Chile, 2007).
} 
Objetivo de Desarrollo Sostenible N4 (ODS4) “Garantizar una educación inclusiva y equitativa de calidad y promover oportunidades de aprendizaje permanente para todos". Por lo visto, al menos en lo discursivo, los enunciados regionales siguen manteniendo una agenda que podría ser direccionada hacia el tema de la calidad y de la evaluación como asuntos centrales, reeditando un esquema que monopolizó la discusión en los '90 y que se corra el eje de la inclusión hacia la problemática de la integración de los "diferentes", o como un asunto atribuible a los individuos.

\section{Sobre la Inclusión Educativa}

El carácter polisémico de la inclusión educativa nos permite una reconstrucción de sentidos, tanto en el plano de la política educativa, como en la vida cotidiana de las instituciones escolares. Desde mi punto de vista, la "inclusión educativa" se fue configurando tanto en un nombre adecuado para ciertas políticas focalizadas, en bandera de lucha de la defensa al derecho a la educación, en tema de agenda de la política internacional y también en política de Estado para la Argentina 20032015. Es claro que no se trata sólo del uso que se le otorga a esta cuestión, sino de un debate vigente, político e ideológico sobre la educación, que disputa sentidos para la inclusión educativa.

Se podría decir en primer lugar que la idea de inclusión ya estaba presente en la concepción de la educación acuñada por los ideales liberales y modernizadores, fundamentados en los principios de la ilustración del siglo XIX. Por ello nos parece interesante presentar un breve repaso por la historia, reseñando cómo se fueron configurando los sentidos que la inclusión connota en la actualidad.

Una gran cantidad de estudios, particularmente sobre historia de la educación, han analizado ampliamente cómo funcionó durante la etapa de consolidación de los Estados Nacionales, la necesidad de incorporación de los individuos a través de la inculcación de normas y patrones culturales comunes considerados válidos universalmente. En ese contexto histórico - político, la organización de los sistemas de enseñanza planteó la formación de ciudadanos, “individuos libres, esclarecidos, ilustrados" y "la escuela fue erigida en el gran instrumento para convertir a los súbditos en ciudadanos, "redimiendo a los hombres de su doble pecado histórico: la ignorancia, miseria moral y la opresión, miseria política" (Saviani, 1983, p. 9). En ese marco, la intencionalidad "liberadora" por la vía de "desterrar" la ignorancia debemos interpretarla desde los ideales de la ilustración, principalmente como redentora, salvadora. O sea, en un sentido de socialización que busca homogeneizar a la población y facilitar la reproducción del orden social (Bourdieu, 1967). La idea de una educación para todos no abarcaba a las élites que conducirían los destinos del país. Otra educación estaría reservada para los ilustrados. Si bien allí la inclusión no aparece explicitada como concepto ni como política, y tampoco sería correcto hacer una transferencia lineal de sentidos, podríamos plantear que en la concepción de una escuela abarcadora en la que todos tienen que estar para convertirse en ciudadanos con valores universales existe ya un germen de cierta manera de entender a la inclusión. Con el tiempo, la cristalización de estas concepciones devendrá en la construcción de un niño universal (el que puede asumir la escolaridad para convertirse en ciudadano) y su contracara en otro niño que necesita ser reparado, rescatado porque no alcanza las expectativas de la escuela. Ese niño "en riesgo" o en desventaja se configura en la comparación como el niño excluido, objeto de intervención por no ser como el niño universalizado. Ese "todos los niños" y el niño excluido son dos tipos distintos de ser humano en la planificación escolar (Popkewitz, 2006).

En la primera etapa de masificación de la escuela, que se puede ubicar a partir de la mitad del siglo XX y con mayor énfasis en el desarrollismo de la década del 60 y con las teorías del capital humano en auge, se acentuó el carácter instrumental de la educación. La pedagogía desarrollista puso el énfasis en la dimensión económica para el desarrollo social y en ese contexto, la educación fue importante como proveedora de mano de obra. Desde esas bases se produjo una ampliación de la metáfora de formar a los ciudadanos (un ciudadano universal), con la de preparar los recursos 
humanos para el desarrollo. Se fue consolidando un ideal del derecho a la educación equiparable al libre acceso, mientras que los sistemas educativos se segmentaban, generando circuitos diferenciados de escolarización en relación con el origen social (Braslavsky, 1985). En esa época, y sobre la base de un "niño universal", la meritocracia fue ganando terreno y sirvió de justificativo para la desigualdad educativa, y así, la carrera abierta al talento se constituyó tanto en la vía de ascenso social como de legitimación de las desigualdades. En este escenario, quedarse afuera del sistema educativo era una situación que revelaba "incapacidad" por parte de las y los estudiantes. La exclusión comienza a configurarse como un problema individual de los sujetos sobre la cual la escuela asume poca o ninguna responsabilidad. Podemos reconocer que aún hoy la lógica meritocrática y competitiva funciona en las escuelas clasificando y jerarquizando a los alumnos, legitimando desigualdades por hacerlas parecer como el resultado del esfuerzo y el talento y haciendo responsable a cada quien de su situación, o sea de la desigualdad (Sverdlick, 2012).

En el terreno educativo, la cuestión de la inclusión remite a conceptualizaciones y políticas de larga data. Al focalizar la mirada en la región latinoamericana, observamos que se suele reconocer la instalación del tema en las agendas regionales e internacionales durante la década del 90 del siglo $\mathrm{XX}$, originalmente relacionado con la integración de los niños, niñas y adolescentes con "necesidades especiales". De hecho, en junio de 1994, la Conferencia Mundial sobre necesidades educativas especiales: Acceso y Calidad, aprobó la Declaración de Salamanca y su marco de acción ${ }^{10}$, cuyo prefacio señala que los documentos allí elaborados "están inspirados por el principio de integración y por el reconocimiento de la necesidad de actuar con miras a conseguir escuelas para todos' esto es, instituciones que incluyan a todo el mundo, celebren las diferencias, respalden el aprendizaje y respondan a las necesidades de cada cual" (Fragmento del prefacio de la Declaración de Salamanca). Sin embargo, y más allá del énfasis que la cuestión de la inclusión comenzó a tener a partir de ese momento, podemos afirmar que, aunque con otras connotaciones,

Con las reformas de los '90 la inclusión emergió recortada en los discursos políticos como una preocupación por las personas con discapacidad, en correspondencia con un modelo de estado nación neoliberal, que concibe a las políticas de inclusión como mecanismos asistenciales que contribuyen a procesos de integración de los grupos subordinados, tradicionalmente excluidos de las políticas públicas. Para el modelo neoliberal, la educación se constituye en un servicio, un bien de consumo que se ofrece a los consumidores; clientes que con sus exigencias y opciones pueden regular la oferta del mercado. Es curioso cómo se invierte el sentido del derecho en función de quién lo enuncia. Si se mira desde este ángulo, en la retórica conservadora, ser "consumidor" presupone un derecho: el de propiedad. En esta concepción, la libertad de comprar y de vender remite al derecho individual que implica usar y disponer de las cosas materiales sobre la base de la libre elección. La ilusión de poder elegir o el mito de la libertad como libre elección para llegar a ser lo que uno quiere y de ir cambiando creativamente parece ser la expresión aggiornada de un nuevo "sueño americano", basado esta vez menos en el esfuerzo personal que en la "oportunidad". Se trata de un mito asentado en la ilusión que en la vida, independientemente de las condiciones particulares de cada quien, las opciones son infinitas, lo cual ofrece la fantasía que "ser libre es convertirse en alguien" (Bauman, 2000). En la lógica neoliberal, el trabajo no constituye un derecho sino algo que se obtiene y gana en relación con la ecuación oportunidades + reglas del mercado + meritocracia y la educación ciudadana remite a la tradicional idea de un ciudadano que "vota bien" y se comporta

\footnotetext{
${ }^{10}$ La Conferencia Mundial sobre necesidades educativas especiales: acceso y calidad, se reunió en Salamanca en 1994 por iniciativa del gobierno español y en cooperación con UNESCO a fin de promover el objetivo de la Educación para Todos examinando los cambios fundamentales de política necesarios para favorecer el enfoque de la educación integradora. Participaron 92 gobiernos y 25 organizaciones internacionales. El documento completo se puede ver en http://www.unesco.org/education/pdf/SALAMA_S.PDF
} 
"bien". Cuando esto alcanza al campo educativo y el Estado se desresponsabiliza, se retira de garantizar un derecho social y la educación pasa a ser un derecho individual que cada cual debe defender, entonces quedan sentadas las bases para la mercantilización de este derecho, donde el Estado se reserva un rol asistencial o caritativo y en definitiva en lugar de hablar del derecho para todos pasamos a hablar de un privilegio para pocos. Recordemos que a mediados de los ' 80 el neoliberalismo impuso una concepción de Estado como proveedor de servicios que se juzga por su eficiencia o ineficiencia con parámetros económicos propios del ámbito empresarial. El discurso de la eficiencia y su relación con la racionalidad es heredero de la época más oscura de la Argentina. Fue durante la dictadura militar (1976-1983), que los diagnósticos oficiales hacían referencia a la "ineficiencia del sistema educativo, aunque sin definir muy claramente qué se entiende por "ineficiencia” (Braslavsky, 1983). Según esta autora "a partir de este diagnóstico, implícitamente referido al funcionamiento inadecuado de las dependencias institucionales, uno de los objetivos explícitos de la gestión educativa fue la "racionalización" de los organismos centrales encargados de planificar y conducir la educación (Braslavsky, 1983, p. 85)

En el siglo XXI, la agenda internacional también se hizo eco de una Latinoamérica que estaba demandando otros aires. La idea de inclusión social y educativa se fue extendiendo y complejizando hasta abarcar "otras inclusiones" vinculadas con la vulnerabilidad social y con los derechos humanos. Entendemos que se trató de una progresiva ampliación de sentido que puede considerarse de algún modo como una conquista, producto de luchas sociales y políticas.

La UNESCO estuvo varios años dándole centralidad al tema y se preocupó por establecer una definición desde el enfoque de derechos. En su portal web de Santiago de Chile se señala que: La inclusión es un movimiento orientado a transformar los sistemas educativos para responder a la diversidad del alumnado. Es fundamental para hacer efectivo el derecho a la educación con igualdad de oportunidades y está relacionado con el acceso, la permanencia, la participación y los logros de todos los estudiantes, con especial énfasis en aquellos que por diferentes razones, están excluidos o en riesgo de ser marginados ${ }^{11}$.

En noviembre de 2008, la 48 reunión de la Conferencia Internacional de Educación titulada: "Educación inclusiva: el camino hacia el futuro", la Organización de los Estados Iberoamericanos (OEI), conjuntamente con la UNESCO introdujeron la idea de un "enfoque de educación inclusiva" al declarar:

Más que ser una cuestión marginal relativa a cómo algunos educandos pueden ser integrados en el sistema educativo regular, el enfoque de educación inclusiva busca transformar los sistemas educativos y los entornos de aprendizaje para dar respuesta a la diversidad de los educandos. Una educación de calidad es entonces una educación inclusiva, puesto que tiene como finalidad la plena participación de todos los educandos.

Y a la vez, se hizo explícito el alcance de la inclusión al decir:

La Educación para Todos debe tener en cuenta las necesidades de los pobres y más desfavorecidos, comprendidos los niños y niñas que trabajan; los habitantes de zonas remotas; los nómadas; las minorías étnicas y lingüísticas; los niños, niñas, jóvenes y

${ }^{11}$ Recuperado de http://portal.unesco.org/geography/es/ev.php URL ID $=8109 \&$ URL DO=DO TOPIC\&URL SECTION=201.html 
adultos afectados por conflictos y desastres naturales, el VIH y SIDA, el hambre o la mala salud; y los que tienen necesidades especiales de aprendizaje ${ }^{12}$.

En Argentina, la instalación de la inclusión educativa como política de estado entre 2005 y 2015 es el reflejo de un posicionamiento político y pedagógico que reconoce el carácter histórico doblemente excluyente de la escuela secundaria: del sistema educativo y de la sociedad (Bourdieu \& Passeron, 1967). A partir de la implantación de la obligatoriedad del nivel secundario en 2006 se intentó promover una escuela menos segmentada, más inclusiva y progresiva. Se buscó tensionar el mandato que tenía la matriz fundante de la escuela secundaria, históricamente caracterizada por su selectivo patrón de normalidad escolar, por un currículum mosaico y enciclopedista, una organización institucional rígida y ritualista, la uniformidad de los procesos de enseñanza y aprendizaje y la formación de un sujeto pretendidamente homogéneo y normalizado (Giovine \& Martignone, 2011).

Este proceso tanto nacional como internacional logró que la mención sustantivada del verbo incluir se connotara positivamente con su sola nominación. En Argentina, durante el año 2015 y bajo el título "inclusión educativa”, el gobierno asoció la inclusión con la justicia social y con el derecho a la educación. En el portal gubernamental oficial de ese año se podía leer que la educación pasaba a ser un tema central y que en virtud de ello, la Ley de Educación Nacional, aprobada en 2006, asumía por primera vez a la educación como un bien público y un derecho personal y social, que debía estar garantizado por el Estado Nacional ${ }^{13}$. El nuevo gobierno que asumió en 2016, de signo contrario al anterior y portando las más duras ideas neoliberales, también connota positivamente a la idea de inclusión, pero su sentido está asociado a la generación de oportunidades, a la calidad, a la jerarquización docente, a la equidad, a la innovación, a la evaluación y al deporte ${ }^{14} \mathrm{y}$ encabezado con una cita de Domingo Faustino Sarmiento ${ }^{15}$ : "Todos los problemas son problemas de educación”. Es esperable que los aires neoliberales que están retornando no sólo a la Argentina, también a la región latinoamericana a partir de 2016, provoquen un retroceso en materia del derecho a la educación y con este retroceso, la inclusión educativa cobrará otros sentidos o quizás recupere los significados del período neoliberal anterior.

¿Cómo llegan estos sentidos a las escuelas secundarias, qué es lo que logran interpelar y eventualmente transformar?

\section{Sentidos y Prácticas de la Inclusión en la Escuela Secundaria}

En una investigación realizada en escuelas secundarias de la provincia de Buenos Aires Argentina durante 2012 y 2014, esas preguntas iniciales estuvieron presentes en la propuesta de analizar cómo se deciden, implementan y realizan las políticas de inclusión en las instituciones, así como también cuáles son las formas de apropiación de las políticas públicas y de generación y gestión de estrategias particulares de inclusión. Al iniciar el trabajo de campo, la variedad de manifestaciones al respecto de para qué, cómo y con qué incluir, evidenció una heterogeneidad de

\footnotetext{
12 Recuperado de http:/ /www.oei.es/noticias/spip.php?article2254

13 http://www.casarosada.gob.ar/politica-de-estado/352-inclusion-educativa Esta referencia puede dejar de estar disponible en cuanto pasen los años ya que se trata de una página gubernamental que cambia según las gestiones.

14 En 2016 la referencia se puede consultar en https://www.argentina.gob.ar/educacion/, aunque es posible que a lo largo de los años, la misma deje de estar disponible ya que se trata de una página gubernamental que cambia según las gestiones.

15 Domingo Faustino Sarmiento es coloquialmente considerado "el padre de la educación" o el "padre del aula” ya que fue quien impulsó y generalizó la educación en Argentina durante el siglo XIX. Personaje controvertido por sus ideas racistas y xenófobas referidas a los indios y a los pobres.
} 
sentidos en torno al concepto de "inclusión educativa", que provocaron nuevos interrogantes sobre los sentidos y tensiones que asume la inclusión en los discursos y prácticas de directivos y docentes y sobre los aspectos de la vida cotidiana escolar que limitan y ponen en tensión dichas conceptualizaciones, discursos y prácticas.

Una primera observación que merece la pena comentar es que los directores y las directoras de las escuelas que participaron del estudio, reivindican su preocupación por la inclusión como un asunto que antecede a cualquier política o normativa gubernamental. Para muchos de ellos, aun reconociendo la incidencia de ciertas normas y proyectos de inclusión derivados de las administraciones locales o centrales en las prácticas concretas y en la construcción de otros sentidos, sus escuelas "ya eran inclusivas" por estar ubicadas en contextos de alta vulnerabilidad social. Es decir, el hecho de "tener adentro" de la escuela a los jóvenes de un barrio marginal, con todo lo que eso conlleva, constituía el desafío de la inclusión educativa para estos directivos. Esta manera de entender la inclusión se nos representó como contracara de la exclusión. Y esta última, connotada negativamente, fue significada como carencia de algo que se contiene en la "inclusión", un "estar fuera" de un adentro que es la escuela. Este enunciado simple presenta a la exclusión como una condición estática que no contempla el carácter de construcción de dicha situación. Entendemos que esta idea deja entrever, por un lado, una concepción idílica de una escuela reparadora de los males que la sociedad no logra mitigar y a través de la cual los excluidos de la sociedad podrían reinsertarse. Aquí se presupone un modelo de alumno y un ideal sobre cómo se debe vivir en una sociedad que no se cuestiona, de tal modo que la inclusión y la exclusión social surgen como dos caras de una misma moneda en la práctica pedagógica (Popkewitz, 2006). En palabras del autor:

La práctica de la enseñanza y el aprendizaje construyen continuum de valores que comparan, dividen y simultáneamente excluyen tanto como incluyen. La pedagogía involucra aspectos culturales acerca de qué es y qué debiera ser el niño. Enseñar es intervenir en las vidas de los niños de manera que sean diferentes a lo que serían si no recibieran educación. Y la historia de esta intervención involucra principios relacionados con cómo vivir esa vida, tales como trabajar corporativamente con otros, aprender cómo negociar en comunidades de aprendizaje y actuar de una manera que permita construir el propio carácter. Esto es parte del relato de la escolarización. La otra parte del relato de la enseñanza - nuevamente una dupla- es que la mejor vida para un individuo está ligada a narrativas colectivas de pertenencia y a la nación como hogar. (p. 5)

Por otro lado y con esta misma lógica, la "inclusión" es asociada a la tradicional tendencia homogeneizadora de la escuela, con su equivalencia discursiva que equipara igualdad y homogeneización (Dussel, 2004). Aquí la inclusión remite a formar parte de un "nosotros" constitutivo de una "identidad escolar" por contraposición a un "ellos", los diferentes / los excluidos (Dussel, 2004). La conformación del "nosotros" en este caso no se trata de una identidad política en el sentido que lo plantea Mouffe (2005) como la constitución de una idea de pertenencia a un grupo de referencia, sino más bien en tanto línea divisoria de quienes participan de un derecho y quiénes no. En este sentido, la exclusión debería interpretarse más que como una condición, como el desenlace de una trayectoria que es diferente a otras que se consideran "normales" y naturales desde un pensamiento hegemónico asentado en el sentido común, o sea como una construcción en la historia singular y colectiva de los individuos (Michi et al., 2009).

Como puede observarse hasta aquí, el uso extendido de la palabra "inclusión" tiene connotaciones positivas en sí misma; de manera tal que la sola referencia a ella nos ubicaría en un lugar "correcto". Ahora bien, si tomamos la idea de Katarina Tomasevsky (2004), quien en su paso por las Naciones Unidas como relatora especial del Derecho a la Educación, denunció que la 
educación, más que un ideal a lograr, podía interpretarse como un genocidio, si por el afán homogeneizador (que tiene como modelo al blanco, occidental y cristiano), se eliminan otras culturas y etnias por la vía de un sometimiento cultural, se podría cuestionar que la inclusión sea inherentemente positiva. En efecto, al asumir acríticamente la inclusión per se, se cae en una postura facilista a la que habría que incomodar con la pregunta ¿incluirse en dónde y para qué?

En las argumentaciones de docentes y directivos, aparecen en efecto los claroscuros y tensiones acerca de la inclusión. Se resalta la importancia casi central de la escuela como espacio de contención para que los estudiantes queden eximidos de estar en la calle, aunque también se menciona la función de aprendizaje de las disciplinas. Por otra parte, el "deber ser", la ley y el peso de la normativa para asumir la inclusión aparece en los discursos de directivos, haciendo explícitas las ideas que emergen de la política de estado (propias del período 2005 - 2015). En este sentido, uno de los directores entrevistados comentó:

Una de las pocas pertenencias que le queda es la escuela, el pibe hoy por hoy tiene la escuela o la esquina (...) Yo siempre jorobo que yo prefiero que el pibe se haga persona y después tenga veinte años para aprender Matemática (...) O sea hay dos cosas que van juntas: el aprendizaje disciplinar y el aprendizaje de hombre genérico (...) Me preocupan las dos cosas por la ausencia de las familias, la ausencia de otro tipo de entidades que puedan moldear, pero moldearlo bien. Sabemos que el adolescente hoy por hoy está expuesto, no es la misma adolescencia que tuve yo en el año 80, no es la misma que tuve en el 2000, ni va a ser la misma que tenga en el 2020 (...) La normativa dice que la secundaria es obligatoria y uno como funcionario tiene que garantizar que el pibe termine la secundaria buscando todos los artilugios necesarios...El chico, hasta que el padre no pide el pase, el chico nunca dejó la escuela. No es como antes (Director de nivel secundario).

Muchos de los adolescentes y jóvenes que hoy concurren a las aulas -estudiantes trabajadores, jóvenes que sostienen su hogar, adolescentes madres o padres, jóvenes embarazadas- desafían la idea de inclusión de docentes y directivos en las escuelas, tensionando su concreción. Se trata de situaciones que aparecen contempladas y atendidas desde la escuela a través de la flexibilidad normativa (en los regímenes de asistencia ${ }^{16}$ y de evaluación) así como con dispositivos de acompañamiento a los jóvenes que no pueden asistir a clases, como en el caso de las jóvenes embarazadas o madres con niños pequeños y trabajadores eventuales. Esto parece aportar condiciones de posibilidad para garantizar las trayectorias de los jóvenes en la escuela, aunque no siempre lo haga en términos de aprendizajes significativos y potentes.

En los relatos, las indiscutidas premisas de "democratizar la escuela" o de "una escuela para todos y todas", que se pregona en los discursos sobre la inclusión educativa como un derecho y como un mandato de justicia social, se enfrentan en la vida cotidiana con una institución escolar históricamente excluyente, diseñada para preparar sólo a una parte de la población. Es así como para docentes y directivos el discurso asentado en la justicia social queda vinculado a garantizar el ingreso y la permanencia de los jóvenes, pero se restringe el sentido de la inclusión a la idea de "estar en la escuela". En ese contexto, para el profesorado, la relación entre masividad y "bajar la calidad" surge como una ecuación sin solución, que no interpela a los contenidos escolares o a las estrategias didácticas. Las cuestiones que atañen a problematizar la enseñanza, los aprendizajes y las trayectorias escolares quedan en un segundo plano frente a esa relación. Y aquí es donde enunciados del tipo: "incluir por incluir no tiene sentido", "así lo único que hacemos es bajar el nivel”, "es mejor que si un chico no quiere estudiar, que no venga a molestar", "hacer pasar a los chicos de cualquier manera

16 Ver Resolución No688/06 DGCE y Ley N¹4637/14 de la Provincia de Buenos Aires. 
es hipócrita" o "se hace mucho hincapié en los derechos pero se olvida de las obligaciones"17, ponen de relieve concepciones muy asentadas en los y las docentes sobre una escuela que parece inmutable.

Resulta interesante esta visión de institución rígida cuando se analiza lo que está prescripto y lo que se hace por tradición, desconociendo de dónde viene dicha forma de hacer. El fraseo mencionado, parece anclar en una idea de escuela sobre la cual se puede operar poco porque todo está preformateado. Al respecto, el análisis que hace Feldman (2009) contradice este imaginario, al mostrar cómo existen prescripciones bastante mínimas sobre contenidos y orientaciones, lo cual, en principio otorgaría un razonable margen de libertad a la institución escolar y a los profesores. Sin embargo, el comportamiento habitual de los actores en las escuelas parece no distinguir aquello que "manda" de manera inexorable de lo que no proviene de las normas legales, sino de las tradiciones. Son muchas las cosas que "se hacen asi" sin que estén prescriptas realmente por la normativa (Feldman, 2009).

Existe tal disociación entre la idea de inclusión y el currículum en la escuela, que al momento de destacar experiencias enriquecedoras de enseñanza y aprendizaje, los directores ponen de relieve proyectos pedagógicos que corren paralelos al currículo oficial, casi sin tocarse, que acontecen por fuera del aula, dando un margen de libertad y participación a los estudiantes como actores claves. Se trata de espacios surgidos a partir de algún programa perteneciente a la política educativa pública y que algunos directores toman para sus escuelas, así como también puede tratarse de proyectos forjados en la propia institución a partir de la propuesta de algún actor institucional, quien "contagia" con entusiasmo al resto. Son propuestas escolares diferentes, en las que los grupos de alumnos se mezclan, donde pueden participar otros actores de la comunidad, y que horizontalizan los vínculos y las relaciones de saber y poder entre docentes y alumnos. Justamente uno de los hallazgos de la investigación se vincula con estos denominados proyectos de inclusión ${ }^{18}$, los cuales parecen contribuir a la ruptura de algunas estructuras escolares clásicas, instaurando nuevas dinámicas y posicionamientos de los estudiantes. Estas propuestas interpelan a los jóvenes en tanto productores de conocimiento a partir de temáticas de interés específico (como la Dictadura en el marco del programa "Jóvenes y Memoria", por ejemplo), promueven su compromiso con actividades por fuera del aula (como salidas recreativas y educativas) y resultan formativas en términos de participación ciudadana. Son experiencias que contribuyen a la generación de un sentido de pertenencia con la propia escuela y la comunidad local, que quiebran la lógica pedagógica y didáctica tradicional, y que promueven espacios de participación y la transversalidad en los grupos de estudiantes.

Entre los proyectos de inclusión mencionados por los directores y docentes en el nivel secundario encontramos una distinción entre aquellos que transcurren por fuera de la dinámica propiamente escolar y se hallan abiertos a la comunidad (como por ejemplo "Patios abiertos" o los "Centros de Actividades Juveniles"), los que se enmarcan en alguna disciplina en particular y buscan modificar el modo de concebir la enseñanza (como el proyecto de "Acción Poética"), y los proyectos que emergen como propuestas transversales a los grupos etáreos dentro de la escuela y trascienden los límites del aula y de la propia institución (como "Jóvenes y memoria" o Parlamentos Juveniles). En relación con el primer tipo, se trata de programas socioeducativos que invitan a entrar

\footnotetext{
${ }^{17}$ Frases seleccionadas, sólo a modo ilustrativo, de diferentes entrevistas a docentes y directivos de escuelas secundarias.

${ }^{18}$ Los directores y directoras consignaron como proyectos de inclusión en sus escuelas a los siguientes: Plan de Mejora Institucional (PMI), Jóvenes y Memoria, Programa Envión, Patios Abiertos, Parlamentos Juveniles, Violencia Cero, Centros de Actividades Juveniles, Acción Poética, jornadas recreativas, viajes y salidas, proyectos de aprovechamiento pleno de la jornada escolar, presentaciones audiovisuales de preceptores acerca de temas de convivencia, entre otros.
} 
y "amigarse con la escuela", pero no necesariamente con lo escolar. Aquí, la escolaridad permanece sin ser interrogada, y su "afueradentro" no contribuye a problematizarla ni problematizarse (Kantor, 2008; Michi et al., 2009). Lo que consideramos el segundo tipo, son iniciativas de un docente en particular o del directivo en alianza con algún docente y quedan acotadas al tiempo y energía que dicho profesor o profesora le pueda poner a la cuestión. Esto es, se trata de propuestas interesantes e innovadoras que se restringen al proyecto áulico de un docente particular.

En relación con el tercer tipo de proyectos, transversales a los grupos etáreos, algunos docentes reconocen que por fuera del aula, los estudiantes se ven interpelados de otra manera por la enseñanza, hacen valer su voz y pueden reconocerse en otros y para otros. Al respecto una docente señala:

Lo positivo es que los chicos ven que la palabra de ellos no queda en el aula, que la palabra de ellos puede transgredir las paredes e irse a otros lugares donde se la escuche, y además de eso, que cuando escuchan al otro, la problemática es la misma (Docente referente de "Parlamentos Juveniles").

En estos proyectos los propósitos son explicitados a los estudiantes y compartidos con ellos desde el primer momento. Tienen una organización secuenciada, durabilidad en el tiempo, y no son evaluados en términos de acreditación de saberes (no son calificados). Los temas, más allá de ciertas condiciones didácticas que generan, proponen y sostienen los docentes o el marco general de los proyectos en los cuales se inscriben, los eligen los alumnos, y son significativos para ellos. Hay lugar para sus inquietudes, sus voces, sus intereses, lo que permite que se desenvuelvan con mayor autonomía. Así, en líneas generales, muchos de los jóvenes que menos participan dentro del aula, que suelen llevar la carga de la estigmatización por ser repetidores, o los considerados "vagos" o "apáticos" y cuyos docentes visualizan de antemano su inevitable fracaso, son estimulados a sumarse a estas propuestas, en las cuales pueden experimentar una mayor igualdad de condiciones con respecto a sus compañeros para participar. En palabras de una docente:

Hemos tenido chicos, por ejemplo, que son súper tímidos, ese perfil de chico que está en el salón y que nunca participa y viene al proyecto y decís "este no es el mismo chico que yo estoy teniendo en el salón”, pero sí, hay una cuestión de compromiso y también muchas veces sirve el tema del grupo, como entre ellos se apuntalan, cuando uno quiere dejar, "no dale, vamos acá, vamos allá" (Docente referente de "Jóvenes y memoria").

En estas experiencias también se produce un estrechamiento de los vínculos, se fortalece la identidad grupal y se produce un mutuo "reconocimiento" entre estudiantes, docentes y directivos. En este sentido, el espacio escolar se resignifica al existir una conexión con los saberes desde el placer, el interés y la curiosidad, no solo entre los estudiantes sino también entre los docentes quienes sienten que "es un lugar de placer y de crecimiento". Es decir que se puede apreciar una inclusión que tiene que ver con aferrarse al espacio escolar a través de uno de sus sentidos primordiales: el aprendizaje. Por otra parte, algunos de estos proyectos comprenden entre sus actividades la realización de excursiones y viajes para la exposición de las producciones y el intercambio con estudiantes de otras escuelas, lo cual alienta a su vez la participación y el compromiso de toda la comunidad. En el marco de estos proyectos es que muchos jóvenes tienen la oportunidad de salir de sus barrios y realizar un viaje por primera vez en sus vidas.

Las iniciativas relevadas y comentadas hasta aquí corresponden a ese tipo de experiencias paralelas al desarrollo del currículum oficial en el espacio tradicional del aula/escuela. Pensamos que es aquí donde se puede ubicar uno de los nudos de la cuestión, ya que, aún con logros significativos en términos de generar pertenencia e identidad, mejor distribución en términos de recursos y hasta 
rupturas significativas en las formas de considerar a los/as estudiantes, si la inclusión educativa no interpela al currículum, ni a los procesos de trabajo de los docentes, podemos estar en presencia de un concepto paraguas que actúa como mandato para "tener los pibes adentro" sin alcanzar a conmover el núcleo duro de la institución escolar: la enseñanza.

El enfoque de Fraser (2006) sobre los paradigmas de justicia distributiva y de reconocimiento puede resultar una de las lentes teóricas valiosas para pensar en las políticas y proyectos de inclusión. Desde el paradigma redistributivo, las injusticias son esencialmente socioeconómicas, mientras que en el paradigma del reconocimiento, se trata de injusticias culturales enraizadas en patrones sociales de representación, interpretación y comunicación. Estos paradigmas no son dicotómicos, sino que componen un enfoque bidimensional en el que "la superación de la injusticia en casi todos los casos exige tanto la redistribución como el reconocimiento" (Fraser, 2006, p. 87). De este modo, una mayor justicia requiere propender a la redistribución y a un mayor reconocimiento entre los sujetos a través de la promoción de la participación y la expresión cultural.

Ciertamente, algunas políticas tienen efectos principalmente distributivos en el campo escolar. Sin desconocer su impacto diferencial en cuanto a cobertura y alcance de la población escolar destinataria ${ }^{19}$, cabe reconocer que las mismas convierten a la escuela en un espacio donde es posible acceder a recursos y experiencias que van más allá de las instancias curriculares básicas. Por ejemplo, la oferta de clases de apoyo en materias previas o con dificultades para la promoción, así como el dictado de talleres extracurriculares (fotografía, teatro, música, ajedrez, etc.) se traduce en una ampliación de las posibilidades de acceso de los estudiantes a apoyos y experiencias cuyo aprovechamiento no queda sujeto a la capacidad socioeconómica de las familias para solventarlas por fuera del ámbito escolar ${ }^{20}$. En este sentido, una oferta académica de este tipo presupone a los estudiantes como sujetos de derecho a la educación, a quienes el Estado debe garantizar la permanencia, los aprendizajes y la promoción.

No obstante, más allá del alcance de las políticas distributivas, conviene detenerse en otros aspectos de lo que se pone en cuestión dentro de la escuela, puesto que una justicia distributiva puede no ser necesariamente justa. Lo citado anteriormente de Tomasevsky (2004), cuestiona justamente la lógica que pregona una justicia distributiva sin reconocimiento, al señalar que resulta injusta una educación que sirva de medio de dominación. El ejemplo que da Terigi (2010) es muy claro al respecto: se puede aprender lo mismo, y estar aprendiendo sin embargo contenidos que confirman o justifican la situación desfavorecida en la que se encuentran aquellos cuya identidad es silenciada o combatida. "Descubrimiento de América", "conquista del desierto", son contenidos que generaciones y generaciones de alumnas y alumnos han aprendido en las escuelas argentinas: son los mismos para todos y todas, y sin embargo, son injustos por etnocéntricos, por arrasar identidades concretas (p. 7). Esta autora, siguiendo a Connell (1993), alerta sobre las limitaciones de las políticas que se fundan en la equidad, en tanto que plantean la necesidad de hacer otras cosas para que todos alcancen los mismos resultados, mientras que en términos de justicia habría que advertir sobre la posibilidad de que esos mismos resultados sean injustos, "si convalidan culturalmente la situación de los menos favorecidos, si obstaculizan el cambio en dirección a la igualdad, si codifican la cultura en sentidos restringidos, etc.” (Terigi, 2010, p. 7).

\footnotetext{
${ }_{19}$ Así se trasluce en los testimonios de algunos actores escolares entrevistados. No todos los estudiantes participan de todas los proyectos mencionados. Al respecto, pareciera que la imposibilidad de que "todos" accedan a las propuestas no aparece delineada como objeto de problematización a nivel institucional.

${ }^{20}$ Los proyectos se inscriben en los Planes de Mejora Institucional que se comenzaron a implementar a partir del año 2010, contemplando diversos tipos de acciones: tutorías y seguimiento de las trayectorias escolares, talleres y clases de apoyo, propuestas didácticas especiales y de acompañamiento a los estudiantes, así como proyectos institucionales para un mejor aprovechamiento del tiempo escolar y la permanencia.
} 
Así, la justicia social parece no alcanzar en términos de su sentido redistributivo a las aspiraciones de una justicia social educativa, puesto que, así como están, las instituciones educativas producen jerarquías, crean identidades sociales y legitiman las desigualdades. Los sistemas educativos meritocráticos y asentados en formas hegemónicas de selección y distribución de cierto tipo de conocimiento considerado válido y universal, fomentan la creencia que las personas favorecidas en la distribución de bienes sociales son merecedoras de su situación de privilegio (Connell, 1993). Por lo expuesto, desde nuestro punto de vista, resulta necesario problematizar la cuestión curricular para complejizar la idea distributiva del conocimiento. Esto es, se trata de poner en cuestión un currículum hegemónico centrado en marginar otras formas de organización del conocimiento, integrado en la estructura de poder de las instituciones educativas y que ocupa todo el espacio cultural, al definir las ideas sobre lo que debe ser el aprendizaje que el sentido común dicta a la mayoría de las personas (Connell, 1993). Al respecto, el autor referenciado propone que la justicia curricular debe suponer una estrategia de "inversión de la hegemonía", el pasaje de una estrategia compensatoria y defensiva a otra proactiva y universalizadora.

Se puede decir entonces que en la tensión que se construye entre inclusión y homogeneización, el currículum escolar resulta clave. El currículum como construcción histórica y social, como proyecto cultural que responde a intereses y a una concepción del mundo y del hombre es un asunto de disputa. En ese sentido, Connell (1993) invita a considerar la justicia en educación conjuntamente con el tema del curriculum y propone tres principios que pueden constituir un modelo operativo de la justicia curricular a través de la implementación de un currículum contrahegemónico: 1) cambiar de punto de partida para encarnar los intereses de las personas menos favorecidas y reconocer la variedad de desigualdades existentes (de género, clase, raza, etnia, etc.), 2) generar prácticas no jerarquizadas de aprendizaje y de cooperación (eliminar las pruebas competitivas, descartar los currículos elaborados desde una única posición dominante y elaborar un "currículum inclusivo" que valore experiencias sociales diversas y desde diferentes puntos de vista), 3) pensar los criterios de ciudadanía participativa y de contrahegemonía de manera conjunta, advirtiendo el carácter histórico de las estructuras sociales que producen la desigualdad. Y aquí es donde cobran especial importancia aquellas formas de participación y de expresión que puedan propender a una mayor justicia del "reconocimiento" de los sujetos (Fraser, 2006) mediante la deconstrucción de los patrones hegemónicos de la política, la cultura y la comunicación. El punto de partida para ello es alentando y fortaleciendo aquellos espacios que favorezcan la plena expresión y participación genuina de los estudiantes en un espacio donde la redistribución sea una realidad.

\section{La Violencia Escolar como Obstáculo a la Inclusión}

Directoras y directores de escuelas secundarias se muestran preocupados por la violencia escolar en relación con las posibilidades de la inclusión educativa. La violencia dentro de la escuela presenta para los actores institucionales un límite a los esfuerzos por "incluir". Se la observa como un elemento que no corresponde a lo escolar; sin embargo, algunos directores logran visualizar que no irrumpe siempre desde afuera sino que muchas veces se origina en la propia escuela. Se reconoce que se ejerce una violencia simbólica en el sentido que lo plantean Bourdieu y Passeron (1967), provocando en los adolescentes una respuesta de violencia explícita que los coloca en el lugar de "los agresores o inadaptados", lo cual refuerza la estigmatización social y dificulta la "inclusión". Esto se expresa en el testimonio de una directora cuando dice "nosotros estamos sometidos a esa violencia pero también podemos llegar a generarla en otro", dejando entrever que la misma es expresión de dificultades de adaptación tanto de los jóvenes hacia la cultura escolar, como de la escuela y los adultos hacia los jóvenes. 
Frente a situaciones que se perciben como ajenas a "lo escolar", los directivos expresan una sensación de impotencia y sienten que no cuentan con herramientas adecuadas para atender estas problemáticas. La violencia provoca inicialmente una perplejidad difícil de afrontar, tal como lo señala una directora:

Cuando alguien agrede, ahí hay otra cosa, ¿cómo hago para que se reinserte al grupo después que dañó a alguien? (...) situaciones como estas vivimos todos los días, ¿cómo seguimos después de una situación de daño? (Directora de nivel secundario)

La separación de los alumnos de la escuela ha dejado de ser una alternativa, particularmente a partir de la nueva legislación. En ocasiones, los temores de la comunidad frente a situaciones de desbordes psiquiátricos, problemas de adicciones, presencia en la escuela del narcomenudeo, son entre otras, cuestiones que se contraponen al mandato inclusivo, sobre todo cuando la falta de recursos no permite viabilizar soluciones genuinas e inmediatas para estudiantes que necesitan algún tipo de asistencia psicológica o médica personalizada.

En un intento por respetar la normativa e incluir a todos y a todas, no como un "deber ser", sino por la propia convicción, hay directivos que piensan que se debe "desarrollar un exceso de imaginación" para generar mecanismos que logren que los alumnos que participan de entornos o episodios de violencia, continúen en la escuela. En este punto aparece valorada la opción de tomar decisiones en un mediano plazo y sin la urgencia del momento. Habitualmente, frente a hechos violentos, la escuela y la comunidad presionan para resolver con inmediatez amenazando la permanencia escolar; sin embargo, tener un tiempo mayor para la reflexión, posibilita un cambio de actitudes por parte de los estudiantes en conflicto y permite una revisión y reconsideración de las propuestas iniciales de resolución. En los procesos de decisión, de discusión y resolución de las situaciones, la implicación de otros actores, más allá del equipo directivo, aparece como una clave para la construcción de acuerdos y criterios institucionales.

Los directivos encuentran que la violencia resulta un obstáculo para pensar en términos de aprendizajes o de experiencias educativas en clave de adquisición de conocimientos. Las cuestiones de índole académica quedan relegadas a un segundo plano y se direccionan los esfuerzos de la gestión hacia la resolución de conflictos que tienen que ver con la convivencia. En palabras de la directora de un Centro de Investigación e Innovaciones Educativas (CIIE) de la Provincia de Buenos Aires:

La cuestión vincular y de los conflictos entre alumnos con los adultos implica un montón de tiempo de tarea que no les permite (a los directores) mirar otras cosas. Y esto termina siendo como un gran combo de complejidades a las cuales, quien accede a una dirección con pocas herramientas tiene que atender, y opacan lo que sería la tarea fundamental dentro de una escuela secundaria que es atender las cuestiones pedagógicas y el trabajo en particular con los docentes, con los adultos, ver qué sucede dentro de las aulas.

Los directores y directoras emplean diferentes estrategias para amortiguar o resolver los episodios de violencia dentro de la escuela, con las herramientas que disponen, amparados o no en la normativa. Tal como señala Feldman (2008), aunque podamos formular intenciones de replantear los propósitos de la escolaridad, es en términos de logros de aprendizaje como se dirimen muchos de los problemas de inclusión/exclusión. No se acepta como argumento educativamente legítimo que mantener jóvenes en las escuelas sea un propósito suficiente -más allá que en las prácticas reales este propósito tenga vigencia principal. La pobreza de los aprendizajes que promueve la escuela no constituye un buen ejemplo de democratización (Feldman, 2008). 
La violencia como obstáculo para la inclusión deja entonces en evidencia un escenario complejo que requiere ser abordado y plantea desafíos a los directivos y los docentes para avanzar en el terreno de la justicia curricular. En este sentido, los sistemas de convivencia y los centros de estudiantes aparecen como instancias privilegiadas para una reestructuración del campo de relaciones escolares que contribuya al procesamiento de los conflictos y la prevención de la violencia (Tilly, 2003, p. 6). El aumento progresivo de los márgenes de participación, autonomía y responsabilidad que observamos no sólo en los proyectos mencionados, sino también a partir de la creación obligatoria de Centros de Estudiantes, pareciera contribuir a una resignificación de la estadía en la escuela por parte de los jóvenes. Probablemente, en la medida que los estudiantes ganan capacidad de decisión, su involucramiento en el orden general, la organización y la disciplina son mayores y evitan la necesidad de muchas intervenciones del mundo adulto (Feldman, 2009).

Nuevamente, aparece la necesidad de cuestionar aquellos mecanismos escolares de dominación cultural y de falta de "reconocimiento", de revisar aquellas creencias, prácticas y relaciones que sostienen el "acaparamiento de oportunidades" escolar (Fraser, 2008; Tilly, 2003). Se trata de reflexionar acerca de cómo la meritocracia y el uso discrecional de las oportunidades modelan expectativas diferenciales de los actores acerca de lo que unos y otros pueden hacer o lograr en la escuela (Tilly, 2003) y rubrican mecanismos de desigualdad social que a su vez son fuente de conflicto escolar. Es una política escolar de "reconocimiento" la que puede establecer una relación de reciprocidad entre los sujetos, lo cual requiere del fortalecimiento de aquellas estructuras democráticas que puedan otorgar visibilidad a los estudiantes como sujetos autorizados a la expresión y la participación.

\section{A Modo de Cierre}

En este artículo se ha intentado relacionar los diferentes sentidos construidos sobre el derecho a la educación, la inclusión educativa y cómo juegan esos sentidos en las prácticas concretas en escuelas secundarias de la Provincia de Buenos Aires.

Una cuestión que parece importante subrayar, tiene que ver con que la lucha que se da en el campo del discurso no es solamente una disputa teórica, discursiva, o una negociación por cómo nombrar con palabras determinados conceptos o categorías, sino que esa lucha también implica la lucha por la hegemonía. Los sentidos que pueden tener las palabras y los conceptos asociados a ellas, ocupan campos que no son solamente campos teóricos o del discurso, sino que también son campos de práctica política. Las palabras, los conceptos, las categorías con las que uno trabaja no son sólo nombres, no son solamente acuerdos o desacuerdos lingüísticos, son definiciones, toma de posición, lucha de sentidos de dominación y sentidos de resistencia. Son luchas de poder.

Así las cosas, y con vientos que soplan neoliberales en América Latina, la resistencia es hoy más importante que nunca, para impedir que vulneren los derechos adquiridos y para continuar insistentemente con una lucha que no es por la inclusión sino por la realización efectiva del derecho a la educación.

\section{Referencias}

Alonso Bra, B. M., \& Sverdlick, I. (2003). La evaluación de las universidades. Un análisis de las perspectivas de gestión de calidad. Revista del Instituto de Investigaciones de Ciencias de la Educación, 21, Facultad de Filosofía y Letras - UBA.

Bauman, Z. (2000). Modernidad líquida. Bs. As., Argentina: Fondo de Cultura Económica.

Bourdieu, P., \& Passeron, J. C. (1967). La reproducción. Barcelona: Laia.

Braslavsky, C. (1983). Estado, burocracia y políticas educativas. En J. C. Tedesco, C. Braslavsky \& R. Carciofi, El proyecto educativo autoritario, Argentina 1976-1982. Buenos Aires: Miño y Dávila. 
Braslavsky, C. (1985). La discriminación educativa. Buenos Aires: Miño y Dávila.

Brener, G. Y., \& Galli G. (Comps.) (2016) Inclusión y calidad como politicas educativas de Estado o el mérito como opción única de mercado. Bs. As. Argentina: Stella.

Ceresani, V. (2012). Los sentidos construidos en torno a la relación entre inclusión escolar y prácticas de educación social. Informe final, ISTLyR. Convocatoria “Conocer para Incidir"-INFD-2009. Mimeo.

Connell, R. W. (1993). Escuelas y justicia social. Madrid: Ed. Morata (edición 1997).

Dussel, I. (1997). Currículum, humanismo y democracia en la enseñanza media: (1863-1920). Buenos Aires: Flacso.

Dussel, I. (2004). Inclusión y exclusión en la escuela moderna argentina: Una perspectiva post-estructuralista. Buenos Aires: Flacso.

Elisalde, R. (2013). Bachilleratos populares y autogestión educativa. Perspectivas y desafíos para la construcción de un movimiento pedagógico en la educación de jóvenes y adultos. En R. Elisalde et al., Movimientos sociales, educación popular y trabajo autogestionado en el cono sur. Buenos Aires: Buenos Libros.

Feldman, D. (2009). La innovación escolar en el currículum de la escuela secundaria. En Romero (Comp.) Claves para mejorar la escuela secundaria. Buenos Aires: Noveduc.

Fraser, N. (2006). La justicia social en la era de la política de identidad: Redistribución, reconocimiento y participación. En N. Fraser \& A. Honnet, ¿Redistribución o reconocimiento? Madrid: Morata.

Giovine, R., \& Martignone, L. (2011). La escuela media bajo el mandato de la obligatoriedad. Cad. Cedes, Campinas, 3(84). Recuperado de: http://www.cedes.unicamp.br

Kantor, D. (2008). Variaciones para educar adolescente y jóvenes. Buenos Aires: Del estante editorial.

Michi, N., Braggio, A., Canciano, E., García, A., Reinoso, V., Villani, P., Kurlat, S., \& Popkewitz, T. (2006). La escolaridad y la exclusión social. Anales de la educación común, 2(4). Provincia de Buenos Aires: Dirección General de Cultura y Educación.

Sverdlick, I. (2006). Apuntes para debatir sobre la gestión escolar en clave política. Una mirada por la situación en Argentina. Revista Electrónica Iberoamericana sobre Calidad, Eficacia y Cambio en Educación, 4(4e), pp. 65-84.

Sverdlick, I. (2009). El derecho a la educación y los movimientos sociales. Otras trayectorias educativas. En G. Misirlis (Comp.) Todos en la escuela. Buenos Aires: UNSAM.

Sverdlick, I. (2012). ¿Qué hay de nuevo en evaluación educativa? Buenos Aires: Noveduc.

Sverdlick, I. (2012). Calidad de educación para todos e inclusión educativa ¿Nuevas banderas para el derecho a la educación? Revista Internacional Magisterio, 56. Bogotá, Colombia: Magisterio Editorial.

Sverdlick, I, Aguilar, L. y Spanarelli, S. (2015) De maestro/a a director/a: Condiciones y contextos en la construcción del oficio. En A. Pereyra et al., Prácticas pedagógicas y políticas educativas: Investigaciones en el territorio bonaerense. Gonnet: UNIPE: Editorial Universitaria

Sverdlick, I., Austral, R., Bloch, M., \& Sánchez, M. (2017) La complejidad de la gestión escolar. Saberes y prácticas. Los desafíos de la inclusión. Buenos Aires. Noveduc.

Sverdlick, I., \& Gentili, P. (2008). Movimientos sociales y derecho a la educación: Cuatro estudios. LPP Buenos Aires.

Tedesco, J. C. (1992). Nuevas estrategias de cambio educativo en América Latina. Boletin del Proyecto Principal de Educacion en America Latina y el Caribe (Santiago de Chile), (28), 7-24.

Tedesco, J. C. (1993). Educación y Sociedad en América Latina: Algunos cambios conceptuales y políticos. UNESCO.

Terigi, F. (2010) Equidad y educación. Evolución conceptual y marcos de análisis. Presentación en el panel: Una mirada sobre los enfoques de equidad de la Reunión Regional de los oficiales y puntos focales de Educación de UNICEF. Buenos Aires. 
Tilly, C. (2003). The politics of collective violence. Cambridge: Cambridge University Press.

Tomasevsky, K. (2004). Los derechos económicos, sociales y culturales: El derecho a la educación.

Organización de Estados Iberoamericanos. Recuperado de

http://www.oei.es/decada/portadas/G0410331.pdf

UNICEF. (2012). Acerca de la obligatoriedad en la escuela secundaria argentina. Análisis de la política nacional.

Recuperado de: https://www.unicef.org/argentina/spanish/doc final 30 08.pdf

\section{Sobre la Autora}

\section{Ingrid Sverdlick}

Universidad Nacional Arturo Jauretche

ingridsver@gmail.com

Doctora en Educación por la Universidad de Málaga, España. Profesora del Instituto de Ciencias Sociales y Directora del Programa de Educación Inclusiva y Pedagogía Universitaria (PREINPU) de la Universidad Nacional Arturo Jauretche, Argentina. Directora de la Carrera de Especialización en Docencia Universitaria de la Universidad Nacional de la Patagonia San Juan Bosco, Argentina. Dirige y desarrolla proyectos de investigación en temas de política educativa, gestión escolar, derecho a la educación y formación docente. Integrante del Grupo de Trabajo de CLACSO (Consejo Latinoamericano de Ciencias Sociales) -Políticas Educativas y Derecho a la educación.

\section{About the Guest Editors}

\section{Nora Gluz}

Universidad de Buenos Aires

Universidad Nacional de General Sarmiento

gluzn@yahoo.com.ar

Doctora en Educación por la Universidad de Buenos Aires, profesora e investigadora del Area de Educación de la Universidad Nacional de General Sarmiento y de la Universidad de Buenos Aires, dirige proyectos de investigación en temas de políticas educativas y desigualdades sociales. Cocordinadora de Grupo de Trabajo de CLACSO (Consejo Latinoamericano de Ciencias Sociales)-Políticas Educativas y Derecho a la educación

\section{Dalila Andrade Oliveira}

Universidad Federal de Minas Gerais

dalilaufmg@yahoo.com.br

Doctora en Educación por la Universidad de São Paulo, profesora de la Faculdad de Educación y del programa de Postgrado en Educación de la Universidad Federal de Minas Gerais. Investigadora del Consejo Nacional de Investigación (CNPq), dirige y desarolla proyectos en temas de políticas educativas, gestión escolar y trabajo docente en América Latina. Co-cordinadora de las International Research Networks (IRNS/WERA) Education Policies e Restructuring of the Educational Profession Facing the Challenges of Globalization. Co-Chair de la Sessión de Educación de la Latin American Studies Association (LASA). Fue co-coordinadora del Grupo de Trabajo do CLACSO - Educación, política y movimientos sociales; vice-presidente y presidente de la Asociación Nacional de Postgrado e Investigación en Educación. 


\section{Cibele Maria Lima Rodrigues}

Fundação Joaquim Nabuco

cibele.rodrigues@,fundaj.gov.br

Doctora en Sociologia por la Universidad Federal de Pernambuco, investigadora de la Fundación Joaquim Nabuco (Fundaj), profesora del Programa de Postgrado en Educación (programa asociado entre la Fundaj e la Universidad Federal Rural de Pernambuco), actualmente coordina el Centro de Estudios sobre Cultura, Identidad e Memória de la Fundaj, dirige y desarolla proyectos de investigación en temas de políticas educativas y movimientos sociales. Co-cordinadora de Grupo de Trabajo de CLACSO - Políticas Educativas y Derecho a la educación

\section{Políticas de Inclusión y Extensión de la Obligatoriedad Escolar}

\section{archivos analíticos de políticas educativas}

Volumen 27 Número $26 \quad 18$ de marzo 2019

ISSN 1068-2341

\section{So}

(c)

SOMERIGHISRESERED LOS/as lectores/as pueden copiar, mostrar, y distribuir este articulo, siempre y cuando se de crédito y atribución al autor/es y a Archivos Analíticos de Políticas Educativas, se distribuya con propósitos no-comerciales, no se altere o transforme el trabajo original. Más detalles de la licencia de Creative Commons se encuentran en http://creativecommons.org/licenses/by-nc$\underline{\text { sa/3.0 }}$ Cualquier otro uso debe ser aprobado en conjunto por el autor/es, o AAPE/EPAA. La sección en español para Sud América de AAPE/EPAA es publicada por el Mary Lou Fulton Teachers College, Arizona State University y la Universidad de San Andrés de Argentina. Los artículos que aparecen en AAPE son indexados en CIRC (Clasificación Integrada de Revistas Científicas, España) DIALNET (España), Directory of Open Access Journals, EBSCO Education Research Complete, ERIC, Education Full Text (H.W. Wilson), QUALIS A1 (Brasil), SCImago Journal Rank; SCOPUS, SOCOLAR (China)

Por errores y sugerencias contacte a audrey.beardsley@asu.edu

Síganos en EPAA's Facebook comunidad at https://www.facebook.com/EPAAAAPE y en Twitter feed@epaa_aape. 


\section{archivos analíticos de políticas educativas consejo editorial}

Editor Consultor: Gustavo E. Fischman (Arizona State University)

Editores Asociados: Armando Alcántara Santuario (Universidad Nacional Autónoma de México), Angelica Buendia,

(Metropolitan Autonomous University), Alejandra Falabella (Universidad Alberto Hurtado, Chile), Antonio Luzon,

(Universidad de Granada), José Luis Ramírez, (Universidad de Sonora), Paula Razquin (Universidad de San Andrés), Maria Alejandra Tejada-Gómez (Pontificia Universidad Javeriana, Colombia)

Claudio Almonacid

Universidad Metropolitana de

Ciencias de la Educación, Chile

\section{Miguel Ángel Arias Ortega}

Universidad Autónoma de la

Ciudad de México

Xavier Besalú Costa

Universitat de Girona, España

Xavier Bonal Sarro Universidad

Autónoma de Barcelona, España

Antonio Bolívar Boitia

Universidad de Granada, España

José Joaquín Brunner Universidad Diego Portales, Chile

Damián Canales Sánchez

Instituto Nacional para la

Evaluación de la Educación,

México

Gabriela de la Cruz Flores

Universidad Nacional Autónoma de

México

Marco Antonio Delgado Fuentes

Universidad Iberoamericana,

México

Inés Dussel, DIE-CINVESTAV, México

Pedro Flores Crespo Universidad Iberoamericana, México
Ana María García de Fanelli

Centro de Estudios de Estado y

Sociedad (CEDES) CONICET,

Argentina

Juan Carlos González Faraco

Universidad de Huelva, España

María Clemente Linuesa

Universidad de Salamanca, España

Jaume Martínez Bonafé

Universitat de València, España

Alejandro Márquez Jiménez

Instituto de Investigaciones sobre la

Universidad y la Educación,

UNAM, México

María Guadalupe Olivier Tellez, Universidad Pedagógica Nacional, México

Miguel Pereyra Universidad de

Granada, España

Mónica Pini Universidad Nacional de San Martín, Argentina

\section{Omar Orlando Pulido Chaves}

Instituto para la Investigación

Educativa y el Desarrollo

Pedagógico (IDEP)

José Ignacio Rivas Flores

Universidad de Málaga, España

\section{Miriam Rodríguez Vargas \\ Universidad Autónoma de \\ Tamaulipas, México \\ José Gregorio Rodríguez \\ Universidad Nacional de Colombia, Colombia}

Mario Rueda Beltrán Instituto de Investigaciones sobre la Universidad y la Educación, UNAM, México José Luis San Fabián Maroto Universidad de Oviedo, España

Jurjo Torres Santomé, Universidad de la Coruña, España

Yengny Marisol Silva Laya Universidad Iberoamericana, México

Ernesto Treviño Ronzón

Universidad Veracruzana, México

Ernesto Treviño Villarreal

Universidad Diego Portales

Santiago, Chile

Antoni Verger Planells

Universidad Autónoma de

Barcelona, España

Catalina Wainerman

Universidad de San Andrés, Argentina

Juan Carlos Yáñez Velazco

Universidad de Colima, México 


\section{education policy analysis archives editorial board}

Lead Editor: Audrey Amrein-Beardsley (Arizona State University)

Editor Consultor: Gustavo E. Fischman (Arizona State University)

Associate Editors: David Carlson, Lauren Harris, Eugene Judson, Mirka Koro-Ljungberg, Scott Marley, Molly Ott, Iveta Silova (Arizona State University)

\author{
Cristina Alfaro \\ San Diego State University \\ Gary Anderson \\ New York University \\ Michael W. Apple \\ University of Wisconsin, Madison \\ Jeff Bale \\ University of Toronto, Canada \\ Aaron Bevanot SUNY Albany \\ David C. Berliner \\ Arizona State University \\ Henry Braun Boston College \\ Casey Cobb \\ University of Connecticut \\ Arnold Danzig \\ San Jose State University \\ Linda Darling-Hammond \\ Stanford University \\ Elizabeth H. DeBray \\ University of Georgia \\ David E. DeMatthews \\ University of Texas at Austin \\ Chad d'Entremont Rennie Center \\ for Education Research \& Policy \\ John Diamond \\ University of Wisconsin, Madison \\ Matthew Di Carlo \\ Albert Shanker Institute \\ Sherman Dorn \\ Arizona State University \\ Michael J. Dumas \\ University of California, Berkeley \\ Kathy Escamilla \\ University ofColorado, Boulder \\ Yariv Feniger Ben-Gurion \\ University of the Negev \\ Melissa Lynn Freeman \\ Adams State College \\ Rachael Gabriel \\ University of Connecticut
}

Amy Garrett Dikkers University

of North Carolina, Wilmington

Gene V Glass

Arizona State University

Ronald Glass University of

California, Santa Cruz

Jacob P. K. Gross

University of Louisville

Eric M. Haas WestEd

Julian Vasquez Heilig California

State University, Sacramento

Kimberly Kappler Hewitt University of North Carolina Greensboro

Aimee Howley Ohio University

Steve Klees University of Maryland

Jaekyung Lee SUNY Buffalo

Jessica Nina Lester

Indiana University

Amanda E. Lewis University of

Illinois, Chicago

Chad R. Lochmiller Indiana

University

Christopher Lubienski Indiana

University

Sarah Lubienski Indiana University

William J. Mathis

University of Colorado, Boulder

Michele S. Moses

University of Colorado, Boulder

Julianne Moss

Deakin University, Australia

Sharon Nichols

University of Texas, San Antonio

Eric Parsons

University of Missouri-Columbia

Amanda U. Potterton

University of Kentucky
Susan L. Robertson

Bristol University

Gloria M. Rodriguez

University of California, Davis

R. Anthony Rolle

University of Houston

A. G. Rud

Washington State University

Patricia Sánchez University of

University of Texas, San Antonio

Janelle Scott University of

California, Berkeley

Jack Schneider University of

Massachusetts Lowell

Noah Sobe Loyola University

Nelly P. Stromquist

University of Maryland

Benjamin Superfine

University of Illinois, Chicago

Adai Tefera

Virginia Commonwealth University

A. Chris Torres

Michigan State University

Tina Trujillo

University of California, Berkeley

Federico R. Waitoller

University of Illinois, Chicago

Larisa Warhol

University of Connecticut

John Weathers University of

Colorado, Colorado Springs

Kevin Welner

University of Colorado, Boulder

Terrence G. Wiley

Center for Applied Linguistics

John Willinsky Stanford University

Jennifer R. Wolgemuth

University of South Florida

Kyo Yamashiro

Claremont Graduate University 


\section{arquivos analíticos de políticas educativas conselho editorial}

Editor Consultor: Gustavo E. Fischman (Arizona State University)

Editoras Associadas: Kaizo Iwakami Beltrao, (Brazilian School of Public and Private Management - EBAPE/FGV, Brazil), Geovana Mendonça Lunardi Mendes (Universidade do Estado de Santa Catarina), Gilberto José Miranda, (Universidade Federal de Uberlândia, Brazil), Marcia Pletsch, Sandra Regina Sales (Universidade Federal Rural do Rio de Janeiro)

\begin{tabular}{|c|c|c|}
\hline Almerindo Afonso & Alexandre Fernandez Vaz & José Augusto Pacheco \\
\hline Universidade do Minho & Universidade Federal de Santa & Universidade do Minho, Portugal \\
\hline Portugal & Catarina, Brasil & \\
\hline Rosanna Maria Barros Sá & Regina Célia Linhares Hostins & Jane Paiva \\
\hline $\begin{array}{l}\text { Universidade do Algarve } \\
\text { Portugal }\end{array}$ & $\begin{array}{l}\text { Universidade do Vale do Itajaí, } \\
\text { Brasil }\end{array}$ & $\begin{array}{l}\text { Universidade do Estado do Rio de } \\
\text { Janeiro, Brasil }\end{array}$ \\
\hline Maria Helena Bonilla & Alfredo Macedo Gomes & Paulo Alberto Santos Vieira \\
\hline Universidade Federal da Bahia & Universidade Federal de Pernambuco & Universidade do Estado de Mato \\
\hline Brasil & Brasil & Grosso, Brasil \\
\hline Rosa Maria Bueno Fischer & Jefferson Mainardes & Fabiany de Cássia Tavares Silva \\
\hline Universidade Federal do Rio Grande & Universidade Estadual de Ponta & Universidade Federal do Mato \\
\hline do Sul, Brasil & Grossa, Brasil & Grosso do Sul, Brasil \\
\hline Alice Casimiro Lopes & Jader Janer Moreira Lopes & António Teodoro \\
\hline Universidade do Estado do Rio de & Universidade Federal Fluminense e & Universidade Lusófona \\
\hline Janeiro, Brasil & $\begin{array}{l}\text { Universidade Federal de Juiz de Fora, } \\
\text { Brasil }\end{array}$ & Portugal \\
\hline Suzana Feldens Schwertner & Debora Nunes & Lílian do Valle \\
\hline Centro Universitário Univates & Universidade Federal do Rio Grande & Universidade do Estado do Rio de \\
\hline Bras1l & do Norte, Brasil & Janeiro, Brasil \\
\hline \multirow{5}{*}{$\begin{array}{l}\text { Flávia Miller Naethe Motta } \\
\text { Universidade Federal Rural do Rio de } \\
\text { Janeiro, Brasil }\end{array}$} & Alda Junqueira Marin & Alfredo Veiga-Neto \\
\hline & $\begin{array}{l}\text { Pontifícia Universidade Católica de } \\
\text { São Paulo, Brasil }\end{array}$ & $\begin{array}{l}\text { Universidade Federal do Rio Grande } \\
\text { do Sul, Brasil }\end{array}$ \\
\hline & \multicolumn{2}{|l|}{ Dalila Andrade Oliveira } \\
\hline & \multicolumn{2}{|l|}{ Universidade Federal de Minas } \\
\hline & \multicolumn{2}{|l|}{ Gerais, Brasil } \\
\hline
\end{tabular}

